WILLIS, Paul. 1991. Aprendendo a ser trabalhador: Escola, Resistência e Reprodução Social. Porto Alegre: Artes Médicas.241pp.

\author{
Deise Maia \\ Eike Freshse \\ Liliam Abram dos Santos \\ Nilma Lino Gomes
}

\title{
Contextualizando a obra...
}

\section{A}

prendendo a ser trabalhador é uma obra que merece ser lida por todos aqueles que se interessam pelas Ciências Humanas, principalmente educadores, sociólogos e antropólogos. O livro é considerado um clássico na área dos estudos culturais em educação. $\mathrm{O}$ autor Paul Willis tornou-se conhecido por seu vínculo com o Center for Cultural Studies Contemporary (CCCS), da Universidade de Birmingham, onde desenvolveu um projeto de pesquisa, de 1972 a 1975, financiado pelo Social Science Research Council, que originou o presente trabalho cientifico.

Além de conter uma extensa e detalhada etnografia da escola, de um estudo realizado com jovens estudantes do sexo masculino, pertencentes à classe operária inglesa, Aprendendo a ser trabalhador possibilitou ao autor a construção de uma crítica às teorias estruturalistas da reprodução ${ }^{1}$, questionando a suposta universalidade, preexistência, impenetrabilidade e antecipação da ideologia dominante a qualquer tipo de crítica.

Contrapondo-se a esses argumentos, o autor evidencia a existência de profundas disjunções e enormes tensões no interior da reprodução social e cultural. Esta perspectiva é o fio condutor de todo o livro, que enfatiza os sujeitos sociais , não como passivos portadores da ideologia, mas enquanto "apropriadores" ativos, inseridos no jogo de produção/ reprodução social por meio de lutas, contestações e uma penetração parcial nas estruturas. A discordância de Willis está na idéia de que o capitalismo 
significa uma dominação totalmente eficaz sobre a classe subordinada.

Nesses termos, sugere uma leitura do capitalismo, em suas formas modernas, democrático-liberais, envolvendo luta permanente. Muitas vezes, aquilo que é considerado uma acomodação da cultura de classe operária pode ser uma forma de resistência desse grupo à ideologia capitalista. Dessa forma, existe uma profunda incerteza e um equilíbrio instável de contradições sempre crescentes no centro do capitalismo.

A etnografia realizada revela a força da cultura operária, que prossegue numa complexa e intensa relação de diferenciação/integração aos valores e ideais da escola e da sociedade capitalista. Mostra ,assim, que há muitas rupturas, distâncias, antagonismos, lutas profundas e uma lógica subversiva real no interior e por detrás dos processos culturais da reprodução, os quais lutam por resultados diferentes daqueles que no momento satisfazem o sistema. Essa incerteza no sistema conduz à compreensão do gigantesco crescimento do estado nos setores de seguridade social e educação, sem perder de vista a questão da unidade/ descontinuidade presente na lógica de reprodução do sistema capitalista. Esse crescimento foi, em alguma medida, imposto ao capitalismo por grupos de competição, utilizando suas próprias liberdades reais (potencializadas pelo próprio capitalismo) para o seu próprio avanço. Embora essas agências estatais ajudem a desviar problemas que o capitalismo produz ,elas não podem ser totalmente absorvidas de volta ao capitalismo.Elas mantêm espaços e oposições potenciais, mantêm vivas questões cruciais, provocando o recrudescimento de oposições e críticas dispensáveis pelo capitalismo. São, dessa maneira, reveladoras de resultados involuntários invisíveis de suas relações e padrões habituais de interação com culturas localizadas e informais.

Desse modo, Aprendendo a ser trabalhador coloca-nos diante de um olhar ampliado (e nem por isso menos autêntico) sobre a análise marxista da educação, explora o paradigma educacional ,que está no centro da relação de ensino das escolas, faz uma crítica ao aconselhamento vocacional e sugere algumas explicações para o persistente fracasso da educação estatal em aumentar as oportunidades de vida das crianças e jovens de classe operária. O livro ainda possui o mérito de introduzir dois importantes aspectos que nem sempre têm merecido a devida atenção dos teóricos da educação, a saber, o gênero e a dimensão cultural. 


\section{O Caráter polifônico da etnografia}

Por que em uma Inglaterra democrática liberal da década de 80 , jovens de classe operária tornam-se operários? Levando-se em consideração que os jovens nessa sociedade podem se auto-conduzir, não sendo obrigados a optarem por um ou outro trabalho, o que faz com que eles acabem em empregos de classe operária, localizados no nível mais baixo da sociedade de classes e concebidos como indesejáveis devido ao fato de ainda se atribuir baixas recompensas ao trabalho manual?

Inquieto em responder a essas e outras questões, Paul Willis examina os aspectos centrais e importantes da cultura operária, a partir de um estudo etnográfico, que se compõe de procedimentos tais como: observação participante, conversas informais e entrevistas com os sujeitos da pesquisa. Estas últimas são contextualizadas e transcritas textualmente, representando as muitas vozes, perspectivas e expectativas presentes no trabalho etnográfico, inclusive as do próprio autor. As intervenções de Willis durante as conversas e discussões não se restringem somente a perguntas, mas também à exposição de suas próprias opiniões. Dessa maneira, o texto etnográfico passa a assumir um caráter de múltiplos autores, pois a voz do antropólogo é mais uma entre as várias vozes ali presentes, e não a única. A presença do autor se dilui dando espaço aos "outros".

Aprendendo a ser trabalhador é uma obra de caráter polifônico. Esse aspecto fica ainda mais evidente quando, ao final do livro, na parte intitulada Apêndice, Paul Willis recupera a voz dos seus informantes e solicita-lhes a sua opinião sobre o significado da pesquisa e do seu papel enquanto pesquisador. Esse encontro foi realizado em 1977 ,após a leitura do rascunho do livro por alguns dos "rapazes".

Ao longo do texto, as pressões e tensões existentes no contexto pesquisado são relatadas, evidenciando a complexidade da realidade estudada. A presença dessas diferentes situações, emoções e tensões são consideradas, pelo autor, de suma importância para a descrição mais completa da cultura desses jovens de classe operária.

Diferentemente de outras pesquisas sobre a relação "trabalho e educação", o presente estudo não apresenta uma conclusão .As considerações do autor sobre a relação entre escola, resistência e 
reprodução social são realizadas ao longo do texto etnográfico, ocupando um maior espaço na segunda parte do livro, denominada Análise - Mais do que concluir, Paul Willis prefere fazer algumas sugestões a curto e médio prazo, a fim de contribuir com uma mudança estrutural de longo prazo e para uma mudança básica nas oportunidades e na qualidade do trabalho enfrentado por esses jovens.

A etnografia não retrata somente as vozes dos "rapazes". O autor também registrou as vozes dos pais , dos professores mais antigos, dos mais novos, e dos responsáveis pelo serviço de orientação vocacional. $\mathrm{O}$ contato com esse último possibilitou ao autor tecer severas críticas a essa prática desenvolvida pelas escolas.

A pesquisa realizada, ao inserir no texto etnográfico as diferentes vozes presentes no cotidiano dos "rapazes", desvelou o serviço de orientação vocacional da escola. Na prática, esse serviço separava os valores dos jovens da sua dimensão cultural, reduzindo-os a características inatas ou internas à própria classe operária. Os aspectos da dimensão cultural, presentes na vida dos jovens de classe operária, eram apresentados, pelo serviço de orientação vocacional, de uma maneira descontextualizada, atomizada e associados às naturezas intrínsecas de empregos particulares. Assim, cada vez mais cristalizavase a idéia de que uns são aptos para pensar e outros para fazer, reforçando a divisão entre trabalho intelectual e trabalho manual.

\section{Apresentando o livro...}

Ao iniciarmos a leitura de Aprendendo a ser trabalhador, defrontamo-nos com o processo de transição ,da escola para o trabalho ,de jovens do sexo masculino e de classe operária, cursando um currículo secundário não-acadêmico e vivendo seus dois últimos anos de escola e seus primeiros meses de trabalho. Para tal, uma metodologia foi escolhida, a saber, um estudo de caso, composto de entrevistas individuais, discussões de grupo e observação participante.

O livro está dividido em duas partes. A primeira intitulada Etnografia, como o próprio nome sugere, apresenta uma descrição da escola e, particularmente, das formas culturais oposicionistas e de classe 
operária que acontecem no interior da instituição escolar. Apresenta, também, uma contribuição prática à literatura sobre a transição da escola para o trabalho, contendo as principais descobertas do autor. A Etnografia é composta dos seguintes capítulos: Os elementos de uma cultura; A forma de classe e a forma institucional assumida pela cultura e Força de trabalho, cultura, classe e instituição.

A segunda parte chama-se Análise e é um aprofundamento teórico sobre o tema tratado no livro. Analisa o significado intrínseco, a racionalidade e a dinâmica dos processos culturais vividos pelos jovens de classe operária, sobretudo, as formas pelas quais esses processos contribuem, de um lado, para a cultura operária em geral e, de outro, de forma imprevista, para a manutenção e a reprodução da ordem social. Essa parte ainda traz uma discussão do processo de formação de estereótipos sexuais em relação ao patriarcado e ao capitalismo e configura-se nos seguintes capítulos: Penetrações; Limitações; O papel da Ideologia; Notas para uma teoria das formas culturais e da reprodução social; A manhã de segunda-feira e o milênio e Apêndice.

Essa divisão do livro não significa, necessariamente, uma separação rígida entre os dados da pesquisa e a interpretação. Uma incursão pela obra permite descobrir que a interpretação etnográfica faz-se presente no decorrer de todo o trabalho. Para realizar a sua análise teórica o autor parte do seu aprendizado na relação com os sujeitos concretos, permeado pela subjetividade presente no trabalho de campo.

O conjunto de preocupações do autor está relacionado ao conceito de força de trabalho e à forma como ela é preparada em nossa sociedade para ser aplicada ao trabalho manual. A força de trabalho é um importante conceito para a compreensão do livro. Nesses termos, segundo o autor, "força de trabalho é a capacidade humana para trabalhar sobre a natureza com o uso de instrumentos para produzir coisas para a satisfação de necessidades e para a reprodução da vida. $O$ trabalho não é uma atividade humana universal, imutável e trans-histórica. Ele assume formas e significados específicos em diferentes tipos de sociedade. Os processos através dos quais a força de trabalho vem a ser entendida subjetivamente e objetivamente aplicada e ,suas inter-relações são de profundo significado para o tipo de sociedade que é produzida e para a natureza da formação particular de suas classes. Esses processos ajudam 
a construir as identidades de indivíduos particulares, assim como formas distintas de classe tanto nos níveis cultural e simbólico, quanto nos níveis econômico e estrutural." (Willis, 1991, p.12)

Ao destacar a importância da construção de uma identidade de classe o autor discute que esta não é verdadeiramente reproduzida, até que tenha passado de forma apropriada pelo indivíduo e pelo grupo e até que seja recriada no contexto daquilo que parece ser uma escolha pessoal e coletiva. "A força de trabalhoé um importante elemento desse processo, pois ela é o principal modo de conexão ativa com o mundo: a forma par excellence de articulação entre o eu e o eu, através do mundo concreto. Uma vez que esse vínculo básico com o futuro tenha sido feito, tudo o mais pode passar por senso comum." (Willis, 1991, p.13)

A partir dessas premissas, Paul Willis sustenta a hipótese de que uma certa idéia subjetiva da força de trabalho manual e uma decisão objetiva para aplicá-la ao trabalho manual são produzidas num lugar específico, ou seja, na cultura contra-escolar operária ${ }^{2}$. É nesse ambiente que os temas operários são mediados até os indivíduos e grupos em seu próprio contexto determinado e onde os jovens da classe operária desenvolvem ,de maneira criativa, transformam e, por fim, acabam reproduzindo aspectos da cultura mais ampla em sua própria práxis. Nesse processo, a própria cultura operária acaba preparando ,de forma eficaz alguns rapazes dessa classe para a oferta manual de sua força de trabalho. Se há a suposição de que existe um processo contraditório de auto-condenação dos rapazes de classe operária, deve-se considerar, entretanto, que tal "condenação" é vivida, de maneira paradoxal, como um verdadeiro aprendizado, como uma apropriação e como uma forma de resistência.

A cultura contra-escolar operária tem sido apresentada, tradicionalmente, pelos próprios educadores e, principalmente, pelos meios de comunicação de massa como comportamentos de violência e indisciplina na sala de aula. Porém, a pesquisa etnográfica realizada pelo autor, mostrou que existe uma base objetiva para a existência de tais sentimentos e processos culturais subjetivos. Esses dois fatores são reveladores da penetração parcial das condições de existência da classe operária .Penetração esta que é muito superior às versões oficiais da realidade e oferecida através da escola e das diversas agências estatais. 


\section{Caracterizando a pesquisa, a escola e os sujeitos...}

A pesquisa é composta de um estudo de caso principal e cinco estudos comparativos. O estudo principal diz respeito a um grupo de doze rapazes de classe operária, que cursavam o currículo secundário, não acadêmico, de uma escola que recebeu do autor o nome fictício de Hammertown Boys, numa cidade chamada Hammertown, no centro da Inglaterra. Na época, essa escola possuía cerca de 600 alunos e continha um número significativo de estudantes pertencentes às minorias oriundas da Ásia e do Caribe. A cidade de Hammertown faz parte de um aglomerado industrial da Midlands.

Paul Willis faz uma descrição detalhada da escola e do seu entorno. Segundo ele, trata-se de uma cidade de classe operária. Apenas $8 \%$ de seus habitantes têm uma ocupação de nível profissional ou gerencial e a grande maioria da população está envolvida em algum tipo de trabalho manual. Há um fluxo diário de várias pessoas de classe média, procedentes do sul e do oeste, que trabalham, mas não moram na cidade. O setor metalúrgico é responsável por mais da metade da força de trabalho total. As outras fontes principais de emprego encontram-se nas indústrias alimentícias, de bebida, de fumo, na engenharia mecânica, veículos, cerâmica, vidro e na distribuição. De um modo geral, Hammertown aproxima-se da cidade industrial típica. Possui todas as características industriais clássicas, assim como, as do capitalismo monopolista moderno, em combinação com um proletariado ,que é ,precisamente, o mais antigo do mundo. Essas características motivaram a escolha dessa escola por parte do autor, pois estavam muito próximas do objetivo da sua pesquisa.

Os alunos eram quase que exclusivamente de classe operária e a Hammertown Boys tinha a fama de ser uma "boa" escola. Tal adjetivo pressupõe, dentro de uma lógica escolar, que a referida escola possuía "padrões razoáveis" de comportamentos e formas de vestir reconhecidos e estava aos cuidados de uma equipe experiente, competente e interessada.

Os sujeitos da pesquisa foram selecionados com base nos laços de amizade e por pertencerem a algum tipo de cultura de oposição (cultura contra-escolar) ,em uma escola de classe operária. 
Segundo Willis, a escola foi construída nos anos de entre-guerras e está situada no centro de um loteamento municipal. Este último foi formado no mesmo período e é muito povoado. É composto de casas comuns, em estado satisfatório de conservação, freqüentemente, possuindo um pátio, interligadas por um labirinto de ruas, becos e ruelas e servidas por inúmeros grandes bares e por conjuntos de lojas e pequenos supermercados.

Durante o período de realização da pesquisa, a escola Hammertown Boys caracterizava-se por ser uma escola secundária moderna, não seletiva, exclusivamente masculina, mas com uma escola geminada, exclusivamente feminina que seguia o mesmo padrão. Após o término da pesquisa, algumas mudanças aconteceram. A escola se unificou (comprehensive) e destinou-se a um único sexo, como parte de uma reorganização geral da educação do município. Em vista dessa futura mudança e sob a pressão dos eventos e em preparação para a Lei de Elevação da Idade de Escolarização Compulsória (RSLA), a escola estava passando por um processo de reforma do prédio e introduzindo ou experimentando algumas novas técnicas durante o período da pesquisa. A prática de divisão em turmas homogêneas ,de acordo com a capacidade, fôra substituída pela divisão em grupos heterogêneos em capacidade; introduziu-se um centro de criatividade, experimentou-se o trabalho em equipe e incluiu-se uma gama de novas disciplinas "opcionais". Tudo isso visando o ano da RSLA.

O contato do autor com o grupo de rapazes pesquisado foi realizado no início do segundo período letivo de seu penúltimo ano escolar. Além do momento escolar, propriamente dito, Paul Willis acompanhou esses garotos nos seis primeiros meses no trabalho (seu último ano coincidiria com o primeiro ano de vigência da RSLA).

Paul Willis realizou alguns estudos de casos comparativos no mesmo período. Eles consistiram de: um grupo de jovens conformistas da mesma classe dos doze rapazes de Hammertown; um grupo de jovens conformistas de classe operária de uma escola secundária vizinha, unificada e mista (em termos de classe), informalmente conhecida como sendo uma escola um tanto mais "pesada"; um grupo de jovens não conformistas de classe operária na escola tradicional (grammar) e unicamente masculina de Hammertown; um grupo similar numa escola unificada próxima ao centro da 
malha urbana maior ,da qual Hammertown faz parte; e um grupo masculino, não conformista (em termos de classe), numa escola do tipo tradicional (grammar) de alto status, na área residencial mais exclusiva da mesma malha urbana mais ampla. Na medida do possível, todos os grupos pertenciam ao mesmo ano escolar, constituíam grupos de amizade e foram selecionados devido ao fato de uma provável saída da escola na idade mínima legal de dezesseis anos. ${ }^{3}$ Todos esses grupos foram selecionados para dar uma dimensão comparativa ao estudo ao longo dos parâmetros de classe, capacidade, regime escolar e atitude frente à escola.

O grupo principal foi estudado por meio de: observação e observação participante em classe, ao redor da escola e durante as atividades de lazer; discussões regulares de grupo, registradas; entrevistas informais; diários. $\mathrm{O}$ autor assistiu às aulas de todas as matérias e outras atividades (não como professor, mas como aluno) assistidas pelo grupo de rapazes ,em vários períodos, e a sequiência completa de sessões de orientação vocacional. Também gravou longas conversas com todos os pais do grupo principal e com todos os professores mais antigos da escola, com os principais professores mais novos, que tinham contato com os garotos e com os orientadores vocacionais que iam até à escola.

Além disso, Paul Willis acompanhou os doze rapazes do grupo principal, assim como os três rapazes escolhidos dos grupos comparativos no seu ingresso no trabalho. A etnografia mostrou que a escolha do emprego pelos "rapazes" não foi norteada pelas aulas de educação ocupacional, mas sim, pela sua cultura específica. Esses jovens buscavam um trabalho em que houvesse um chefe e que se configurasse uma situação do tipo "eles e nós". Partiam do pressuposto de que todo trabalho era desagradável e o que realmente importava era o salário e o potencial das situações particulares em proporcionar momentos de prazer, de diversões, de risadas para si, tal como foi aprendido na cultura contra-escolar.

Durante a pesquisa, quinze períodos curtos de observação participante foram dedicados a trabalhar lado a lado com cada um dos rapazes em seu emprego, terminando com entrevistas gravadas individualmente e entrevistas selecionadas com supervisores, gerentes e delegados sindicais. $\mathrm{O}$ autor percebeu como um ponto comum nas duas culturas (contra-escolar e chão de fábrica), a disseminação de estratégias que visavam arrebatar o controle do espaço simbólico e real da autoridade oficial. 


\section{A cultura contra-escolar...}

A cultura contra- escolar possui como característica principal a oposição cerrada, nos planos pessoal e geral, à autoridade. Esse sentimento é verbalizado pelos "rapazes" (lads - o título que os integrantes da cultura contra-escolar escolheram para si próprios). Essa oposição expressa-se principalmente como um estilo. Manifesta-se de várias maneiras, que são próprias da instituição escolar e que são rapidamente reconhecidas pelos docentes, constituindo-se uma característica quase ritual da trama diária da vida dos rapazes.

Os "rapazes" apresentam um comportamento típico. Especializamse numa animosidade reprimida, que se situa no limiar do confronto aberto. Optam por distribuírem-se, na sala de aula, de maneira a sentarem-se o mais perto possível um dos outros, a fim de formarem um grupo. Quando da sua permanência em sala, há um contínuo arrastar de cadeiras, uma ação contrária a qualquer tipo de solicitação e uma contínua agitação ,demonstrando os mais diferentes modos de se sentarem ou se estenderem na cadeira. Durante o estudo individual alguns abertamente mostram indiferença, fingindo dormir, olhando pela janela, fitando o vazio, o teto e as paredes. Existe um ar indefinido de insubordinação, com justificativas evasivas e impossíveis de serem flagradas.

Ser um dos "rapazes" não se restringe a um determinado tipo de comportamento e identidade no interior da escola. Essa identidade está associada também com o "sair" à noite e desenvolver uma compreensão social não apenas da escola, mas também do bairro, da cidade e das ruas.

Os "rapazes" elegem alguns alvos para acertarem os seus ataques principais. Além das autoridades escolares, eles sentem prazer em se opor àqueles que se conformam à "idéia" oficial da escola, mais precisamente, os conformistas ou "cê-dê-efes". Pare eles, esses colegas têm uma orientação muito diferente, pois apoiam a idéia de professor, acordam com a instituição escolar, estão sempre "ouvindo", nunca "fazendo". Estão sempre numa posição de recepção rígida e nunca movidos por sua própria vida interna. Os "rapazes" sentem-se superiores aos "cê-dê-efes". A maneira utilizada para expressar essa superioridade é através da diversão, independência e emoção. Só os "rapazes" sabem fazer uma boa farra.

Ainda existem outros aspectos que realçam o sentimento de 
superioridade dos "rapazes" em relação aos conformistas. A experiência sexual, a maneira de se vestir e de se pentear (cabelos longos e bem cuidados, sapatos tipo plataforma, camisa com uma grande gola branca dobrada sobre casacos acinturados ou jaquetas jeans, além das ainda obrigatórias calças boca-de-sino), o uso do cigarro e do álcool. Os três últimos, apesar de serem apropriados de forma diferente pela classe operária para os seus próprios fins, são apresentados no livro como três representantes dos bens de consumo fornecidos pelo capitalismo.

A relação entre a cultura da escola e a cultura contra-escolar dos "rapazes" pode ser entendida como um exemplo clássico da oposição entre o formal (a escola) e o informal ( a cultura contra - escolar). Nesta última, as exigências invasivas do formal são negadas. A oposição presente na cultura operária é geralmente assinalada em direção ao informal, expressando-se, de maneira peculiar , precisamente para além do alcance da "norma".

Porém, mesmo que não haja normas públicas, estruturas físicas, hierarquias reconhecidas ou sanções institucionalizadas na cultura contra -escolar, ela funciona através de uma lógica própria.. Ela tem que se apoiar sobre uma base material, que representa a sua própria infra-estrutura. Essa base material é o grupo social. O grupo informal é a unidade básica dessa cultura, a fonte fundamental e elementar de sua resistência. É através do grupo informal que o posicionamento dos "rapazes" e todos os outros elementos da cultura tornam-se possíveis e a sua existência serve para distinguir ainda mais estes últimos dos "cê-dê-efes".

Mesmo sendo informal, o grupo dos "rapazes possui regras que podem ser visivelmente descritas, mesmo que elas apresentem um esquema de ação que desobedeça àquilo que normalmente se entende por "regras". Uma delas é o tabu da delação.A delação infringe a essência da natureza informal do grupo.Aquele que delatou ou, na linguagem dos "rapazes" ,que "dedurou" não importa quem, é visto como fraco e fica para sempre marcado.

O grupo possibilita a troca e o intercâmbio não- oficial com outros grupos do bairro com os quais os jovens de classe operária se fundem e se vinculam formando uma rede para a transmissão de tipos distintivos de conhecimento e de perspectivas que, aos poucos, colocam a escola numa posição tangencial, em relação à experiência de ser um adolescente 
de classe operária ,numa cidade industrial. É a infra-estrutura do grupo informal que torna possível um contato distinto de classe, ou cultura de classe que difere os seus integrantes da classe dominante.

A cultura contra-escolar tem também uma forma desenvolvida de trocas que se baseia em pequenos furtos, trapaças e na obtenção de um dinheiro extra através da venda de objetos furtados, um padrão que está presente também no mundo operário adulto.

O livro ainda aponta mais um traço definidor de ser um dos "rapazes": a risada. A capacidade de fazer com que os outros riam é algo peculiar desses jovens. Ela também é usada para vencer o tédio e o medo, para enfrentar situações difíceis. A risada é um instrumento privilegiado do informal, assim como a ordem de mando é do formal. Sendo assim, os rapazes sabem da importância simbólica da "risada".

A etnografia ainda nos mostra que nem sempre os "rapazes" estão atrás de estimulantes vítimas externas para suas "risadas". A interação e a conversação entre eles, geralmente ,tomam a forma de "gozação" ou "tirar sarro". Esta é, muitas vezes, dura e dirigida contra os mesmos indivíduos, pelas mesmas coisas. Frequientemente, a "gozação" é atribuída à falta de inteligência e esperteza de alguém, o que é, no mínimo ,curioso, já a que essas duas características estão muito próximas dos valores convencionais da escola que eles tentam resistir. Esses garotos mantêm um contato físico constante, porém marcado pela rudeza de gestos como chutes, socos, golpes de karatê, quedas de braços, empurrões, e rasteiras, estendendo-se por longos períodos e dirigidos a indivíduos particulares, chegando muitas vezes às lágrimas. Essa fachada de dureza é o traço de um certo tipo de masculinidade e se amplia muito mais à noite, na rua e, particularmente, nas danças em uma discoteca de propriedade particular.

Os "rapazes" demonstram também atitudes machistas e racistas. Os dois grupos através dos quais o seu senso de superioridade se manifesta são o das garotas e o das minorias étnicas. Às garotas não se concede nenhuma identidade particular, exceto aquela de sua atração sexual. Eles classificam as mulheres em duas categorias: a namorada e a "garota fácil". A namorada é a parceira doméstica real que lembra o papel desempenhado pela mãe e a "garota fácil" é aquela que é sexualmente experiente.

Quanto às minorias étnicas, a própria estrutura da escola reforça o racismo. Segundo Paul Willis, é visível a presença de três grupos distintos 
- caucasianos, asiáticos e antilhanos - nas diversas situações escolares. Porém, embora esses grupos estabeleçam contatos individuais ,principalmente na ala juvenil, a partir do quarto ano eles são claramente separados na distribuição das turmas. Essa prática mostra ,de maneira clara ,os padrões informais de cultura racial ,subjacentes às estruturas oficiais da escola e ,algumas vezes, por ela obscurecidos.

O racismo na cultura contra-escolar é estruturado por estereótipos reificados, mesmo que sejam diferenciados. Alguns grupos, como os asiáticos, estão em maior desvantagem e geralmente são os alvos preferidos de intimidações e provocações, de golpes físicos e simbólicos à sua pertinência étnica, uma atitude muito comum entre os rapazes. Essa baixa expectativa diante das minorias raciais não está presente só entre os "rapazes". Durante as entrevistas com professores e autoridades da escola, o autor pôde captá-la na fala daqueles que são responsáveis pelo processo pedagógico.

\section{Cultura contra - escolar e cultura operária ...}

Apesar de se expressar por meio de diferentes formas aparentemente criativas e auto-criadas de oposição e de estilo cultural, a cultura contra-escolar não é um mero produto da escola. O livro insiste na necessidade de contextualizá-la dentro do universo cultural da classe operária, destacando que ,a oposição criada pelos "rapazes" não é algo acidental e nem o seu estilo dotado de uma total independência. Embora o autor reconheça os efeitos específicos da cultura contra-escolar, ele os coloca dentro do padrão mais amplo da cultura operária. Só assim será possível compreender a sua verdadeira natureza e significado.

Para conseguir captar esse universo cultural mais amplo foi necessário que a etnografia extrapolasse os limites escolares e se realizasse nas fábricas, em que esses jovens conseguem se empregar, após deixarem a escola , e , também ,que se incluísse entrevistas com os pais dos "rapazes" em suas casas.

Essa amplitude do trabalho etnográfico possibilitou o desenvolvimento da seguinte hipótese: a cultura contra escolar possui muitas e profundas semelhanças com a cultura para a qual os seus 
membros estão destinados - a cultura do chão de fábrica. Apesar da dureza do trabalho nas fábricas, os operários buscam o seu significado e impõem referenciais de sua cultura, exercitando suas capacidades e buscando prazer na atividade, até mesmo onde são muito controlados pelos outros. Contraditoriamente, eles tramam, através da experiência morta do trabalho, uma cultura viva que em nada se associa à idéia de derrota. Tal atitude é muito semelhante àquela desenvolvida pela cultura contra-escolar no interior da escola.

Segundo o autor, essas culturas não são um mero amortecimento diante das condições indignas impostas pelo capitalismo. São apropriações, movimentos, atividades, exercícios de habilidade e recriações e possuem fins específicos.

Dessa forma, a masculinidade e a dureza da cultura contra-escolar refletem um dos temas centrais localizados na cultura de chão de fábrica. Uma espécie de chauvinismo masculino, que pode ser visto através das atitudes dos trabalhadores, do seu discurso e na representação simbólica da mulher. Os cartazes de mulheres em poses sensuais colados nas paredes se misturam às máquinas cheias de óleo.

Outro tema comum às duas culturas é o esforço para se obter o controle informal do processo de trabalho. O "fazer cera" ou "fazer corpo mole" tem sido uma prática freqüente dos trabalhadores, já analisada desde a perspectiva de gerência de Taylor. ${ }^{4}$ Trata-se de um esforço ainda que informal para conseguir um certo controle do processo desgastante da fábrica.

As formas distintivas e muito desenvolvidas de linguagem e de humor intimidatório do chão de fábrica são também consideradas um tema comum entre a cultura de chão de fábrica e a cultura contra-escolar. Elas se constituem de brincadeiras, gozações e provocações.

Um outro ponto, comum entre as duas culturas, e que foi percebido graças ao trabalho etnográfico, diz respeito ao sentimento de onipresença ,por parte dos "rapazes", de que eles sabem mais coisas do que os outros. No chão de fábrica existe, também, um sentimento de que a prática é mais importante que a teoria. Enquanto o conhecimento e as qualificações são vistos como um valor positivo para a classe média, aos olhos da classe operária, a teoria está vinculada a práticas produtivas particulares. Caso contrário, ela deve ser rejeitada. 
A cultura do chão de fábrica baseia-se, igualmente, na unidade organizacional fundamental da cultura contra-escolar, a saber, o grupo informal. $\mathrm{O}$ grupo informal supõe uma força social que se exprime na lealdade, na sustentação de objetivos e opiniões grupais para a sua continuidade .É uma prática coletiva que adquire forma e sentido e projetase como um espaço potencial em relação ao sistema mais amplo. No chão de fábrica são criadas estratégias dos trabalhadores para driblar o peso do trabalho. É o momento da troca e a base para se conseguir faturar um extra, com objetos "furtados" da fábrica. Nesse caso, a "delação" também é um ato não permitido. Aquele que denuncia ao supervisor esse tipo de prática dos colegas recebe como punição o ostracismo.

Sendo assim, o livro mostra que é a dimensão mais ampla de classe que possibilita à cultura contra-escolar operária sua vantagem, criatividade, estilo próprio e sua particular força de oposição, porém, ao mesmo tempo, ela acaba preparando os "rapazes" para o ingresso nos empregos de classe operária. Ela termina, ensinando a esses jovens a serem trabalhadores.

O autor chama a atenção para o importante papel das culturas de classe. Elas são criadas especificamente, de maneira objetiva, por meio de condições determinadas e de oposições particulares. Elas são diversas, não se caracterizam como um todo homogêneo.

Elas surgem através de lutas decisivas, ao longo do processo histórico, com outros grupos, instituições e tendências.

A cultura contra - escolar gera nos "rapazes" um desprezo pela escola, pelos conformistas, pelos padrões de classe média, pelo trabalho intelectual. .A forma, como o trabalho mental e o trabalho manual são apresentados aos alunos reforça uma divisão de classe e de cultura. Os dois tipos de trabalho são associados às classes antagônicas e aos dois principais grupos de alunos presentes na escola, os che-dê-efes e os "rapazes". Para estes últimos, o trabalho manual tem uma importância capital. Além de lhes garantir uma certa autonomia financeira, ele reforça um sentimento de masculinidade, possuindo um caráter simbólico de agressividade e de afirmação.

Para os "rapazes", o trabalho manual representa o trabalho do mundo adulto diferentemente dos conformistas, que são incapazes e precisam de qualificações, porque não têm imaginação e perspicácia para fazer as coisas de outra forma. Segundo os "rapazes", o importante 
é "saber alguma coisa sobre o mundo", "dar duro". Essa perspectiva é reforçada pelo mundo operário adulto, em que se valoriza muito mais a prática do que a teoria.

Willis apreende daí que a conjunção do antagonismo de classe e o paradigma educacional transformam a educação em controle , a resistência de classe numa recusa educacional e as diferenças humanas em divisões de classe.

Ao ingressarem na fábrica, a celebração da cultura do "chão de fábrica" tem pouca duração para os "rapazes". A curto e médio prazo, o trabalho manual satisfaz no sentido de garantir aos jovens o recebimento de um salário e pelo fato de agora trabalharem sob condições difíceis com pessoas mais velhas e duras. Porém, quando o chão de fábrica passa a ser visto como uma prisão, a educação torna-se o único escape.

O trabalho mental carrega consigo $a$ ameaça da exigência à obediência e ao conformismo. Esse tipo de trabalho é sempre associado aos grupos a que os "rapazes" se opõem dentro da escola , os "cê-dê-efes" e aos professores. Ele é também associado à inferioridade social da feminilidade.

A "preparação" para o trabalho se dá, na escola, no espaço da orientação vocacional. Os professores, muitas vezes, bem intencionados, acabam por reforçar essa divisão entre trabalho manual e trabalho mental, através dos filmes exibidos aos alunos, das falas e da escolha dos conferencistas. Os "rapazes" tecem severas críticas às práticas de orientação vocacional desenvolvidas pela instituição escolar.

\section{Cultura escolar, cultura operária, ideologia e capitalismo...}

O autor faz uma afirmação, no mínimo polêmica, para os defensores de um marxismo rígido. Segundo ele: "É bastante errado descrever a cultura ou a consciência operária, otimisticamente, como a vanguarda na grande marcha em direção à racionalidade e ao socialismo. Se alguma coisa pode ser dita - o argumento central desse livro - é que são esses elementos de racionalidade e de futuro da cultura operária e, particularmente, da cultura da escola, que atuam, ao fim e ao cabo, em sua forma social atual e de forma complexa e involuntária, para impedir 
precisamente isso. É a aparente ascensão cultural da classe operária que traz o inferno de seu próprio e real presente" (Willis, 1991,p.155).

Porém, ele mesmo relativiza essa negatividade e argumenta que embora haja muitas barreiras, ainda resta o fato de que "a classe operária é a única classe não inerentemente estruturada a partir do interior pela complexidade ideológica da organização capitalista" (Willis,1991,p.155).

O livro também sugere uma importante interface entre a cultura e a ideologia. Essa interface consiste no fato de que a ideologia atua sobre e através do cultural. Ela produz a cultura e em parte é produzida por ele. "A ideologia é, ela mesma, em parte influenciada pela produção cultural, e por isso apresenta uma força e uma efetividade no interior de processos culturais." (Willis, 1991, p.196)

O ensino e a orientação vocacional são as forças ideológicas mais explícitas a incidir sobre "os rapazes" durante a sua preparação para o trabalho. Eles acabam confirmando um certo "lugar" dos rapazes de classe operária na estrutura capitalista e podem também deslocar o olhar dos mesmos de uma das questões centrais que envolvem a relação capital/ trabalho, ou seja, a lógica produtiva do capitalismo. Durante as aulas de orientação vocacional, essa lógica é apresentada com um certo naturalismo, como se a opressão, resultante de uma determinação advinda da organização social de pensamento, produção e interesses ,fosse algo natural, resultado de mil e uma causas externas. A ênfase no individualismo, na boa preparação para a competitividade ,tudo reforça essa idéia, quebrando a possibilidade de se construir laços de solidariedade. Os "rapazes", ao rejeitarem esse tipo de concepção, estão deixando de se envolver por esse discurso. Porém, ao mesmo tempo, eles compreendem a sua "vocação" voltada mesmo para o trabalho manual, não aspirando outras formas de realização profissional. Uma das maneiras encontradas para apresentar essa oposição está na rejeição à idéia de qualificação para o trabalho dada pela escola. Para eles, essa é uma ilusão dos cê-dê-efes e da classe média, pois o que realmente qualifica é a prática.

Contudo, nem só de ilusão vivem os "rapazes" operários de classe trabalhadora. Eles também possuem insights sobre a natureza do capitalismo, conseguem vislumbrar caminhos, escapes e lançar luzes sobre essa realidade, a ponto de criarem uma cultura contra-escolar, encontrando meios de burlar as regras, as sanções, a autoridade do professor, a própria 
estrutura da escola, bem como o individualismo e a suposta diversificação do trabalho manual defendida pela escola.

\section{Fazendo as considerações finais...}

O estudo em questão propõe o desenvolvimento de uma teoria mais geral das formas culturais e seu papel na reprodução social. Coloca sob suspeita uma compreensão demasiadamente reducionista ou puramente materialista do nível cultural. Segundo o autor, as formas culturais não são "determinadas" como um reflexo automático, por determinantes macros, tais como localização de classe, região e nível educacional. Essas variáveis são importantes e não podem ser esquecidas. Mas "de que forma" elas influenciam o comportamento, a fala e a atitude? A existência de determinantes estruturais e econômicos não significa que as pessoas se submeterão a eles sem maiores reações. Para melhor compreendermos esse complexo processo é preciso ver qual é o poder simbólico da determinação estrutural no interior do campo mediador do humano e do cultural. De uma certa maneira, os determinantes macros precisam, para se reproduzir de alguma forma, passar pelo milieu cultural.

Para entendermos ,o fato de "como e por que" os jovens de classe operária assumem os empregos restritos e, freqüentemente sem sentido, através de formas que lhes parecem coerentes em seu mundo familiar, é preciso ir ao milieu cultural tratado nesse livro e aceitar uma certa autonomia dos processos que se dão ao nível cultural. Tais processos, ao mesmo tempo, colocam por terra qualquer noção simplista de causação mecânica e concedem aos sujeitos sociais uma atuação significativa, reconhecidamente humana e não teoricamente reducionista. A escolha pelo trabalho manual não deve ser vista como uma experiência incoerente, na qual os indivíduos deixam de ter a lucidez devido as influências culturais perversas. Ela também não representa uma experiência de total inocência, profundamente influenciada pelas ideologias preestabelecidas. É uma experiência que tem a natureza profana de si própria: ela não se apresenta sem um significado, nem somente com o significado que lhe é dado pelos outros. Ela só pode ser vivida ,porque partilha de uma autenticidade e é auto - construída, sentida subjetivamente, como um profundo processo de aprendizagem: é a 
organização do eu em relação ao futuro. As formas culturais proporcionam os materiais para a construção de subjetividades e a confirmação da identidade e seu contexto imediato. Elas marcam e dão sentido à vida.

Neste ponto, o estudo levanta uma importante questão que, no início dos anos oitenta e noventa, ainda não era considerada com a devida importância nos estudos sobre educação e trabalho, ou seja, a relação entre trabalho, cultura e subjetividade.

A cultura ocupa um lugar de destaque na argumentação do autor. Como sustenta, ela não é estática e nem tampouco composta de categorias invariantes que possam ser deduzidas ao mesmo nível em qualquer tipo de sociedade. A essência do cultural e das formas culturais, na sociedade capitalista ,está na sua contribuição para o processo de reprodução criativa, incerta e tensa advinda de diferentes tipos de relações. A reprodução cultural sempre carrega consigo uma importante capacidade: a possibilidade de produzir.

O autor reafirma a sua crítica às teorias reprodutivistas. Desse modo, argumenta que as formas culturais não podem ser reduzidas e nem vistas como epifenômenos de fatores estruturais básicos. Elas são parte de um círculo necessário, no qual estrutura e cultura não podem ser pensadas em separado. É na passagem através do nível cultural que as relações estruturais objetivas da sociedade são transformadas em relações conceituais e viceversa. "O cultural é parte da necessária dialética da reprodução."

E a escola? O estudo mostra que embora a escola não seja eficaz ,da maneira como ela deseja ser, não se pode negar a sua importância. Ela é um dos motivos do renascimento de uma cultura oposicionista de classe , vivida por uma grande parte dos garotos de classe operária durante o terceiro, o quarto e o quinto anos. Esse renascimento produz mudanças na ocupação subjetiva da força de trabalho. Através das contradições e das maneiras involuntárias, a cultura contra-escolar realiza para a educação um de seus principais, embora não-reconhecidos, objetivos - a condução de uma parte dos garotos de classe trabalhadora, "voluntariamente" para o trabalho manual qualificado, semi-qualificado e desqualificado. $\mathrm{Na}$ realidade, antes de causar uma ruptura ou uma "crise" na educação, a cultura contra-escolar e os processos que ela promove acabam ajudando a impedir uma crise real.

Não basta apenas a introdução de idéias progressistas, chamadas pelo autor de "progressivismo", para a realização de mudanças na 
organização institucional da escola. O "progressivismo", desenvolvido e teorizado como uma ideologia oficial por acadêmicos, em conjunção com movimentos democráticos sociais, políticos e institucionais mais amplos, tenta aumentar as oportunidades e o acesso para a classe trabalhadora. Ao nível prático, entretanto, esse progressivismo é adotado nas escolas como uma solução prática para problemas práticos, sem causar uma mudança nas filosofias básicas de educação. Ao nível cultural, o "progressivismo" muitas vezes causa um efeito contraditório e involuntário. Ele reforça os processos, no interior da cultura contra-escolar ,que são responsáveis pela preparação subjetiva particular da força de trabalho e aceitação de um futuro de classe trabalhadora, que é justamente o contrário das intenções progressivas em educação.

Porém, essa análise não representa uma descrença do autor no progressivismo. Ele reconhece que esse movimento e o RSLA (Lei de Elevação da Idade de Escolarização Compulsória) têm atacado problemas reais e protegido os garotos, durante um tempo, da vida árdua e da desigualdade da indústria e tem lhes proporcionado, mesmo que de forma involuntária, alguns insights e avanços culturais que não estavam ao alcance de seus pais. Porém, não devemos nos portar de forma ingênua diante dos avanços. É preciso questionar "sob que forma, para quem, em qual direção e através de que círculos de involuntariedade, com que conseqüências produtivas para o sistema social em geral, avanços particulares são efetuados" (Willis, 1991, p.218).

Diante do exposto, o leitor poderá perguntar: em que a etnografia ajudou no estudo realizado pelo autor? Deixamos a resposta para o próprio Paul Willis: "a descrição etnográfica, apesar de todos os seus defeitos, registra um nível crucial da experiência e, através de seus viesses, enfatiza um nível da agência humana que é persistentemente negligenciado ou negado, mas que cresce em importância o tempo todo para outros níveis do todo social. Embora o mundo não seja nunca diretamente "conhecível" e não possa empiricamente apresentar-se da forma que a descrição etnográfica parece algumas vezes sugerir, ele deve, não obstante, ser especificamente registrado em algum lugar na teoria se a teoria aspira ter qualquer relevância. As teorias devem ser julgadas, em última instância, pela adequação que apresentam em relação a si mesmas. Este livro tentou, especialmente na Parte II, aproveitar as vantagens ainda oferecidas por 
um método qualitativo para responder descritiva e teoricamente a um nível real e difícil da existência social, ao mesmo tempo em que tentou resistir às tendências ao empiricismo, ao naturalismo e à objetivação dos sujeitos" (Willis, 1991, p.236).

\section{Notas}

${ }^{1}$ Ver discussão de Paul Willis citando ALTHUSSER, L. Ideology and Ideological State Apparatuses. In: Cosin .B.R.(ed).Education, Structure and Society. Penguin, 1 972. Apud.Willis, 1991, p.209-213.

${ }^{2} \mathrm{O}$ conceito de cultura contra-escolar será abordado com mais detalhe no decorrer do texto.

${ }^{3}$ De acordo com o autor, no caso da escola tradicional (grammar) de alto status, a condição de idade mínima de dezesseis anos determinou totalmente a escolha do grupo e sua característica de ser de classe social mista - eles eram os únicos rapazes que intencionavam deixar a escola aos dezesseis anos no quarto ano escolar (quando o autor teve o contato inicial com o grupo) e, de fato, subseqüentemente, apenas dois deles realmente deixaram a escola nesse ponto. (Willis,1991,p.16)

Como sistema de exploração industrial ,baseado nos princípios de organização racional do trabalho, o taylorismo pretendia aumentar a utilização eficiente e racional das forças de produção. Ver: TAYLOR. F. W. Scientific Management.Greenwood. Press,1 972 . Em sua época, Taylor estava trabalhando contra o " fazer corpo mole" e o "fazer cera", mas a própria racionalização e expansão da produção produzidas dessa forma por suas técnicas criam as condições para um maior controle informal do processo de trabalho. A manipulação e o controle das forças de produção trazem consequiências reais visíveis para as relações sociais de produção que retroagem, elas próprias, sobre aquelas forças.(Willis, 1991, p.222.)

Deise Maia é professora de Antropologia do Departamento de Ciências Sociais da UEL e doutoranda pela USP.

Eike Freshse é mestranda em Educação pela USP.

Liliam Abram dos Santos é mestranda em Letras pela USP.

Nilma Lino Gomes é professora da Faculdade de Educação da UFMG e doutoranda em pela USP. 